\title{
DIÁLOGOS DESCLASSIFICADOS Música e corpo-arquivo na construção de um saber inacabado primeiros passos
}

DECLASSIFIED DIALOGUES Music and archive-body in the construction of an unfinished knowledge (firststeps)

Erickinson Bezerra de Lima ${ }^{1}$ Universidade de Aveiro erickinson.bezerra@ua.pt

Klênio Barros ${ }^{2}$ Universidade de Aveiro kleniojbarros@ua.pt 


\section{Resumo}

O presente estudo parte do reconhecimento da crescente importância da noção de corpo-arquivo para a compreensão das práticas performativas, mais especificamente, quando aplicadas à música. Esta proposta de reflexão tem ganhado forma devido à expansão de um processo de classificação estrutural presente no cotidiano das nossas sociedades e que nos tornam cegos de outras realidades pos- síveis. Nesse contexto, formulamos um pensamento crítico sob essa lógica ao mesmo tempo em que destacamos certas inquietações importantes para os performers e que interessam aos musicólogos. O objetivo central é perspectivar a aplicação do conceito de corpo-arquivo no domínio dos estudos musicais. Partindo de um conjunto de aproximações, o artigo, por um lado, apresenta e desenvolve as maneiras através das quais é possível, a partir da desclassificação, levar a cabo essa aplicação. Sob outra perspectiva, este trabalho procura analisar as maneiras pelas quais os próprios músicos destacam esse processo face às suas experiências performativas'.

Palavras-chave: Música; corpo-arquivo; classificação/desclassificação; tion of Knowledge.

\section{Abstract}

The present study is part of the growing recognition of the importance of the archive-body for the understanding of the more specific performance practices when applied to Music. This proposal for reflection has been taking shape due to the expansion of a structural classification process present in the daily life of our societies and which has become a reason for other possible realities. In this context, we formulate critical thinking under this logic while highlighting certain questions that are important for artists and that are of interest to musicologists. The main objective is to allow the application of the concept of body-file in the field of musical studies. Starting from a set of approaches, the article, on the one hand, presents and develops as ways in which it is possible, from the disqualification, to carry out this application. From another perspective, this work can analyze how the musicians highlighted in this process face as their performative experiences.

Keywords: Music; Archive-Body; Classification/Declassification; Construcconstrução de saberes.

\footnotetext{
${ }^{1}$ Regente norte-rio-grandense e atuante nas vertentes artísticas e acadêmicas do estado (RN). É doutor e mestre pela Universidade de Aveiro (Portugal) em Regência Orquestral, pós-graduado em Regência com ênfase em Música Contemporânea e Música de Câmara e licenciado em Música pela UFRN. Desenvolveu atividade docente na área de Regência na Universidade Federal do Rio Grande do Norte.

${ }^{2}$ Técnico em Música (2005), bacharel em Música (2009) e pós-graduado em Música (2011)- Práticas Interpretativas do Século XX e XXI (UFRN/ Brasil). É mestre em Música (2014), pela Universidade de Aveiro (Portugal). Atualmente, é doutorando em Música da Universidade de Aveiro, no ramodaetnomusicologia. Desenvolveu atividadecomo docentedetrombone, tubae bombardinona Universidade Federaldo Rio Grandedo Norte.
} 


\section{A gênesis das inquietações}

Não há melhor tarefa para um estudioso inquieto do que desconstruir certezas. Isso porque a maior perturbação para um estudioso é o medo de não ser livre. Seremos claros. Há leituras que são capazes de nos arrebatar de tal modo que certas ideias nos surgem com tremendo ímpeto no plano intelectual. Ideias que, mesmo por um pe- ríodo curto de tempo, nos fazem levitar, que, já numa primeira aproximação, deixam qualquer um a sorrir. É como se, por instantes, talvez, tirássemos os pés do chão. Elas "solucionam" ou, pelo menos, "parecem solucionar" imediatamente tantas inquietações fundamentais que parecem assegurar também a resolução mais ou menos duradoura de todos os questionamentos essenciais e/ou esclarecer todos os pontos obscuros. $\mathrm{O}$ que quer que possa ser ou ter sido, ela serve, num presente que transborda, como um espectro para nos afugentar de certos modos de pensar e nos encaminhar para outros. $E$, como os modos de pensar de que estamos sendo afastados nos parecem mais convincentes do que aqueles para os quais somos lançados, nós gostaríamos de fazer algo a esse respeito.

A música, como fenômeno ou como domínio conceptual, nos parece um bom exemplo para pensar essas questões, especialmente quando, no interior das suas práticas, o exercício da contradição movimenta uma espécie de terremoto em nosso sistema lógico. Ademais, "grande parte do fenômeno que designamos por música não tem uma existência física no sentido em que não o podemos segurar, fixar ou concretizar" (SARDO, 2018, p.9). De acordo com a autora, e a mesma inspirada no modo como Elizabeth Travassos e Marta Ulhôa se referem à voz, a música parece ser "uma realidade fugidia" (SARDO, 2018, p. 10).

Surgem outros questionamentos na ordem das contingências: se a música nos foge, de que forma podemos guardá-la? Como situar em nível teórico as situações efêmeras intrínsecas à prática da música e que toca intima- mente corações, histórias pessoais e culturais? Quando pensamos em guardar essas práticas, onde é que as guardamos? E, se guardamos, o que efetivamente guardamos? Vamos por partes.

Num primeiro instante, algumas ideias conceptuais nos seduzem pela avidez de alguma nova forma de ciência, ou o epicentro em termos conceituais em torno do qual pode ser construído um horizonte de análise abrangente e promissor. De acordo com a filosofia de Susanne Langer (1996), a moda repentina de tal ideia, que exclui praticamente outras possibilidades semânticas por um momento, tem a ver com o fato de todas as mentes sensíveis e/ou ativas se voltarem logo para explorá-la. De imediato, tendemos a fazer uso delas em cada conexão, enxergamo-la em tudo que vemos, experimentamos cada extensão possível de seu significado preciso, e assim por diante.

Não obstante, ao nos aproximarmos intimamente dessa nova ideia, isto é, após ela se tornar parte do nosso repositório geral de conceitos teóricos, diz Clifford Geertz (2008, p.3), "nossas expectativas são levadas a um maior equilíbrio quanto às suas reais utilizações, e termina [então] a sua popularidade excessiva”. Alguns devotos, que permanecem com os olhos vendados, continuam em sua opinião anterior sobre ela. De outra forma, pensadores menos apegados e extremamente preocupados em descobrir - referimo-nos àqueles que se autopercebem como socialmente encaminhados para 
"fora do lugar comum" -, após algum tempo de reflexividade, fixam-se nos problemas que a ideia gerou efetivamente.

O impulso primeiro é buscar aplicá-la ou ampliar a sua compreensão a partir do diálogo com a "vizinhança". Se a transposição é realmente frutífera, num primeiro ins- tante, assumimo-la como duradoura no nosso arsenal intelectual. Todavia, depois de algum tempo, não terá mais a competência de aplicação que um dia já teve (GEERTZ, 2008), porque, segundo a filosofia sartriana (2005), por maior que seja a força de coer- ção, o "Outro", na forma de pensar e de agir, pode se manifestar a qualquer momento. É preciso então desclassificar lógicas cerradas, quebrar hierarquias, instalar pluralismo lógico (GUTIÉRREZ, 2007, 2018), promover uma ecologia de saberes, descolonizar o império cognitivo (dominante) que se organiza à nossa volta e que nos faz "cegos" (de uma outra realidade possível), aprender "com" e "a partir do" Sul metafórico (SANTOS; MENDES, 2017), deixar a porta aberta, seguir os actantes ${ }^{3}$ (LATOUR, 2012), percorrer pelas teias de significados que eles teceram e ver como eles próprios resolvem esses problemas.

Da forma como entendemos, não há nada distinto da realidade a que se possa atribuir um sentido previamente dado. Pelo contrário, tudo pode acontecer, porque as realidades (socialmente construídas) são dinâmicas e, como tal, permanecem em aberto (BERGER; LUCKMANN, 2010), à procura de sentido. Nos termos de Silvia Cusicanqui ${ }^{4}$ precisamos de "conceitos encarnados" capazes de propor uma "teoria enraizada" - isto é, que tem a sua raiz na pluralidade das experiências e que não nega a sua história/genealogia própria para a compreensão do mundo. Para Langer (1996), a transformação simbólica é uma atividade essencial da mente humana. Por conseguinte, o poder criativo e articulador dos símbolos é o motor principal que move e/ou toca profundamente nossos mestres ${ }^{5}$ nos mais diversos campos do conhecimento e da vida.

Ora, não sabemos efetivamente se esse processo ocorre com todos os conceitos relevantes no âmbito das Ciências Sociais e Humanas. No entanto, esse padrão se confirma no caso do conceito de corpo-arquivo, quando aplicado à música.

O conceito de corpo-arquivo que este estudo seguirá está intimamente ligado ao pensamento de Daniel Tércio, no sentido em que ele nos oferece ferramentas particulares para pensar, no que diz respeito à música, a problemática do "arquivar performances". Para Tércio, o fundamental está em "perceber como é que as acumulações que vão sucedendo numa lógica de arquivo se rebatem sobre um corpo presente" (TÉRCIO, 2017, p.106). Por conseguinte, a noção de corpo-arquivo se traduz num corpo capaz de construir uma certa historiografia autoral e única, porém, móvel. Por essas e outras razões, a proposta de Daniel Tércio, que advoga o corpo como arquivo, se tornou muito importante para as nossas preocupações no domínio dos estudos em performance musical. De forma insubmissa - que tende a ser livre - e inquietante, o seu pensamen-

\footnotetext{
3 De acordo com Bruno Latour (1999), é preferível fazer uso do termo actantes em vez de atores. Aos nossos olhos, este termo é relevante porque faz referência à heterogeneidade dos indivíduos que atuam como mediadores e que produzem efeitos nas redes de associações.
}

4 Historias... (2018).

5 Para efeito do que temos vindo a argumentar, concebemos o "saber" como algo que porta todo e qualquer ser humano. Nesse sentido, nossos avós ou nossos pais, por exemplo, são tão mestres quanto pode ser um autor famoso da Filosofia. 
to convoca a desclassificação do corpo, uma operação que nos oferece um terreno absolutamente fértil para pensar o modo como tratamos e nos relacionamos com as músicas.

Se, por um lado, entendemos amplamente a "música via corpo" como uma realização performativa que "está cativa do acontecimento e, portanto, tem uma existência evasiva e intermitente" (SARDO, 2018, p. 10). Por outro lado, quando pensamos em "arquivo via música", somos encaminhados, historicamente, às diversas "tentativas desesperadas de a capturar com recurso a diversos dispositivos de registo, ou seja, de fi xação do acontecimento" (SARDO, 2018, p. 10). Seguindo essa mesma 'perspectiva, "estas operações encerram um verdadeiro paradoxo: tentamos fixar o objeto como forma de o tornar evidente, presente, concreto e, todavia, defendemos que a inevidência, a abstração e o movimento são a condição da sua existência" (SARDO, 2018, p. 10).

Em outras palavras, podemos erguer a partir de Sardo (2018), que essas operações descortinam uma contradição particular: "tentamos fixar o objeto como forma de o tornar evidente, presente, concreto e, todavia, defendemos que a inevidência, a abstração e o movimento são a condição da sua existência" " (SARDO, 2018, p. 10).Propomos como hipótese que as práticas musicais associadas à música popular espelham as mesmas experiências de instabilidade que o próprio corpo-arquivo tem como processo de construção de um "saber inacabado" 6 .

Não obstante, a música é uma das áreas do saber que mais tem estado sujeita à violência da classificação. O desconforto é flagrante quando, "tentamos escrever ou falar sobre música [e] não sabermos como nomeá-la” (SARDO, 2018, p. 09), ou quando nos deparamos com músicas de culturas distantes. No seu texto "O desconforto de escrever sobre música" Susana Sardo sustenta este argumento através do seguinte exemplo: "enquanto para a tradição erudita ocidental, baseada no temperamento igual, a nota lá obedece a uma vibração absoluta de 440 Hertz, noutras tradições musicais todos os sons se constroem a partir de uma afi nação móvel" (SARDO, 2018, p. 11). Do mesmo modo, "categorias musicais que a indústria da música tem vindo requintadamente a amplificar como as de música popular, música folclórica, música de protesto, música erudita, música regional, ou a intraduzível world music" (SARDO, 2018, p 11), constituem exemplos classificatórios que dependem do lugar a partir do qual as nomeamos.

Noutros casos, é igualmente perturbador perceber que, para alguns ouvidos, Hermeto Pascoal representa um músico popular brasileiro, embora, para ou- tros, seja um músico de jazz, para outros soa até como música contemporânea, e assim por diante. O fato é que todos esses exemplos refletem um itinerário de classificação, ou melhor, nos termos de Garcia Gutiérrez (2018), "de violência classificatória".

Aquilo que queremos partilhar aqui é, no fundo, resultado de um trabalho profundamente empírico, nomeadamente, das conversas que temos diariamente com os músicos e das reflexões que nós fazemos dentro e fora dos palcos.

Somos filhos de uma geração que se formou enfrentando desafios diversos e tendo que lidar, cada vez mais, com a mudança repentina das coisas, como nenhuma outra sociedade historicamente precisou.

6 Em paralelo ao autor García (2011), no presente trabalho, a utilização do termo "saber inacado", é alusivo ao fato de compreendermos a construção do conhecimento como algo que está em constante flúxo de construção. 
Cada vez que subimos no palco para atuar com ou- tros músicos, aprendemos a (re)definir as coisas com as quais trabalhamos e/ou sobre as quais falamos, e uma das coisas que fazemos muito é tentar definir o que efetivamente a música comunica ou pode comunicar.

Confirmamos, então, que o estudo em arquivos convencionais pode ser, em alguma medida, relevante, porém não consegue dar conta de examinar uma parcela significativa do discurso musical - aquela que mais nos interessa. Referimo-nos aos processos sociais provenientes das interações e das formas dinâmicas de arquivar saberes. Estes não se podem encontrar visíveis em arquivos tradicionais, tal como nas partituras, por exemplo. A reflexão sobre isso permitiu-nos enquadrar a música dentro da paisagem de um corpo sensível à arte e permanentemente incompleto por natureza. Daí o nosso interesse no conceito de corpo-arquivo, capaz de fazer emergir um conhecimento-outro - para usar a expressão de Garcia Gutiérrez (2007).

\subsection{Espedaçando: a lógica da desclassificação}

Se seguirmos as ideias de Gutiérrez (2007), acedemos ao mundo e nos relacionamos com ele através de uma atitude classificatória - algo do qual não conseguimos fugir com- pletamente. Embora não contestemos a sua força criadora, a lógica da classificação parece-nos ter chegado ao ponto em que confunde muito mais do que esclarece. Al- gumas das significações que os próprios performers constroem dentro da sua expe- riência pessoal é disso um bom exemplo. A tendência é se preocupar, cada vez mais, em limitar, especificar, enfocar e conter significados, como se eles fossem válidos para tudo ou preexistissem independentemente do contexto, isto é, de estarem enquadra- dos num paradigma específico de aplicação. É justamente essa redução dos conceitos a uma dimensão justa/unívoca (quase que inquebrável) que nos encaminha a (re)pensar a aplicação do conceito de corpo-arquivo no âmbito dos estudos musicais ligados à performance, em suas diferentes formas e direções.

Antes de tudo, primeiramente, o que se pode compreender efetivamente por "classificação"? E por que temos a classificação? Talvez porque temos a "desclassificação". $\mathrm{E}$, se temos a desclassificação, em que contexto aparece essa lógica? Qual a sua especificidade teórica e analítica?

A inspiração conceptual parte do domínio dos estudos em Epistemografia ${ }^{7}$, opondo-a a Epistemologia. Se a Epistemologia [ocidental], que atende a lógica da classificação, é comumente vinculada ao conhecimento ordenado verticalmente e elitista porque termina por ignorar grande parte do conhecimento socialmente produzido — a Epistemografia - por sua vez, propõe uma lógica de organização do conhecimento de forma horizontal, interativa e que pode fazer emergir aquilo que está oculto ou excluído (GUTIÉRREZ, 2007, 2014). Para apresentar essa concepção, centramo-nos nas propostas do professor espanhol García Gutiérrez (2006, 2007, 2018), que convoca a tese da "desclassificação".

7 Este campo procura estudar a forma como os conhecimentos se encontram organizados (GUTIÉRREZ, 2014). 
Ao longo da história, a lógica dominante impôs dogmas e múltiplas repressões, absolutamente redundantes, em relação às formas humanas de autopercepção do mundo que habitamos. Uma dessas opressões sistemáticas - reiterada em cada tratado, em cada teoria, em cada afirmação inquestionável e cotidiana - aparece, através de uma autorreflexão crítica, especialmente quando nos vemos obrigados a aceitar um governo/controle de uma lógica dominante, única ou universal e que, se analisarmos bem, nega uma condição fundamental da nossa existência, que é a diversidade humana (GUTIÉRREZ, 2007).

Segundo Gutiérrez (2007), a classificação, como realidade objetiva (formação de conceitos duros e suas hierarquias), parte de uma lógica única, convencional, coercitiva e, como tal, é, na maioria das vezes, opressora e absolutamente contrária à diversidade. A percepção de Gutiérrez tem a ver com o fato de entender que o ato de classificar tem um paradoxo perverso: "ocultar conhecimento". A aposta é justamente na desclassificação, que implica o aparecimento do que está oculto/submerso, como diria Gutiérrez (2007), daquilo que está confinado às favelas do conhecimento ${ }^{8}$. Logo, a desclassificação configura um sistema aberto, que instala pluralismo lógico e é abordado desde uma perspectiva paraconsistente (mais à frente veremos o que isto significa e as suas implicações).

Surge, então, essa ideia de que várias lógicas - o que Gutiérrez (2007) chamou de conhecimento-outro - se contrapõem aos processos de constituição de uma verdade única que dominou o pensamento conservador/tradicional durante muito tempo na história ocidental e que ainda hoje impõe as fronteiras do que é possível e do que não é possível realizar em nossas sociedades. Ora, essa abertura para a emergência de várias lógicas possíveis é o que Garcia Gutiérrez designou por "pluralismo lógico".

Posto isso, a principal estratégia para fazer emergir um "conhecimento-outro", desclassificado, seria valer-se das "contradições". Ou seja, a prática das contradições seria uma alternativa possível de orientar o pensamento num movimento contrário com relação àquilo que é imposto violentamente. $O$ conceito de contradição, durante muito tempo, foi entendido no Ocidente como algo completamente desconectado do mundo exterior. Digamos que ela se dava num plano interior/subjetivo e tinha que ser resolvida intimamente. É neste sentido que reduzir a compreensão de "corpo" ao seu significado biológico e manter estático o pensamento remitente ao que compreendemos sobre "arquivo" consistiriam, como exemplo na presente abordagem, em uma violência epistemológica.

De outra forma, progressivamente, muitos pensadores começam a perceber efetivamente que cada afirmação/classificação é, no fundo, paraconsistente, ou seja, é constituída intimamente por várias lógicas simultâneas e até contrapostas ${ }^{9}$. As contradições são, hoje, cada vez mais, utilizadas na construção do pensamento crítico, indispensável para a transformação da(s) realidade(s).

8 ver Cientificamente Favelados (GUTIÉRREZ, 2006).

9 No tópico que trata sobre a narrativa dos músicos veremos como as paraconsistências se expressam 
Muitos estudiosos, sociólogos e an- tropólogos, como Boaventura de Sousa Santos e José Manuel Mendes (2018), Bruno Latour (2012), García Gutiérrez (2007), dentre outros, utilizam esse conceito como uma ferramenta poderosa para desconstruir situações de opressão, de violência epistemoló- gica e de hierarquias fortemente organizadas. Em síntese, as contradições nos mostram que nada é definitivo. Por essa razão, elas estão intimamente ligadas ao movimento e/ ou à ideia dos fluxos.

No caso do conceito de paraconsistência, este vem justamente trazer esperança às contradições (GUTIÉRREZ, 2007). Partimos da ideia de que cada classificação - cada entidade única - é, na verdade, paraconsistente. Ou seja, não possui uma consistência efetiva para se manter como uma unidade inquebrável. Hoje, sabemos que cada fenômeno está cativo do seu acontecimento e das particularidades próprias da situação específica desse acontecimento. É o caso do conceito de corpo-arquivo, quando aplicado à música.

\section{Corpo-arquivo: uma abordagem musicológica}

A viagem do corpo e tudo o que vai com o corpo

(primeiraaproximação)

Ao longo do tempo, as práticas musicais acompanharam a migração da humanidade (CÔRTE-REAL, 2010) numa viagem para outros portos. O movimento dos indivíduos e tudo o que estes levam consigo resultou em processos de inclusões, aceitações sociais, reinvenção cultural e jogos de identificação - daí que o binômio música e migração sugere a metáfora da "viagem". É nesta viagem que os indivíduos, para além dos pertences físicos que carregam, transportam também, no próprio corpo, uma constelação de saberes (BARROS, 2016, p.79-80).

Na literatura, muitos dos estudos migratórios relacionados à música - segundo autores como: Sardo, 2010; Martínez, 2010; Ribeiro, 2010; Côrte-Real, 2010 - têm demonstrado que todo mo- vimento de pessoas implica também o movimento das músicas que praticam em seu lugar de origem, dado que a música é um dos comportamentos humanos mais portá- veis. Podemos levá-la conosco para onde formos, porque "levamo-la dentro do corpo". A música que está incorporada podemos levá-la a qualquer lugar - na perspectiva de Sardo (2010; 2018).

Esta reflexão sintetiza um pensamento que se distancia de um corpo definido às margens da medicina, composto de membros e órgãos, não limitado às ações convencionais para sua existência. Um corpo que perpassa o que lhe é comum e se estrutura perante a arte, notadamente, a música, como elemento sensível de conectividade com o mundo. 
O corpo tem sido alvo de diferentes sentidos e formas de significar. Não é possível considerar a produção artística na ausência de um corpo. Isso porque ele está no centro da produção artística. Derrida (2001) colocou a seguinte questão: o que acontece com o arquivo quando ele se insere no próprio corpo?

Digamos que a noção de arquivo é largamente compreendida como uma instância ou lugar de acesso a um fato - presente ou passado. Existe uma ideia comum de que o arquivo é algo que pode ser cuidado, que pode ser (ou não) reproduzido, mas que, sobretudo, pode ser acedido. Do ponto de vista das práticas musicais, sabemos que a performance se faz por corpos e em corpos. Ou seja, realiza-se completamente nesse momento de contato corpo a corpo - envolvendo músicos, não músicos, audiência, produtores culturais, comunidades que acompanham as performances etc. Quando a realidade performativa cessa, entre músicos e não músicos, a performance fica guardada também em $\operatorname{corpos}^{10}$.

Dentre as várias formas de pensar os arquivos ou o processo de arquivamento de performances, aquelas que mais facilmente se encaixam nos moldes aos quais as bibliotecas estão habituadas são as mais parciais, uma vez que o arquivo vivo das performances musicais, aquele que permite não só a lembrança, mas também a recuperação dos conteúdos mais sensíveis - da criação, verdadeiramente - é o próprio corpo.

O performer, ao aprender e treinar e fazer e repetir performances, toma-a para si. No entanto, seu corpo não está como uma tela em branco, porque ele é memória e, como tal, é uma espécie de "corpo território", que consegue articular a plenitude do corpo enquanto sua interface de vivência e contato com o mundo.

A dança dos corpos: o repertório das ações (Terceira aproximação)

Se torna pertinente o pensamento de Newton: "para toda ação há uma reação". A atividade performativa está atravessada por três dimensões: um passado que remete a um arsenal de ações outrora incorporadas; um tempo presente que envolve a abertura para uma realidade possível em rumo a um tempo futuro resultante de uma intenção criativa, porém, inacabada. Em suma, a própria ação performativa consiste como catalisador que provoca a ação necessária de evocação dos elementos necessários à sua realização.

Numa situação concreta de performance, diferentemente da situação de estudo individual, o performer experimenta, de forma particular, o lugar onde seu discurso toca intimamente as pessoas. 
Isto é, numa performance ao vivo, o convívio musical e social perante a diversidade de gerações de músicos e públicos, proporciona a emersão de linguagens inovadoras que se rebatem no corpo enquanto arquivo.

Seguindo essa mesma linha, o repertório de ações incorporadas envolve um pensamento social específico: o diálogo entre o eu e o(s) outro(s). Nesse diálogo, vários significados são incorporados. São discursos que provocam ou potencializam provocações musicais que atingem o corpo como arquivo. Este é estimulado a produzir respostas no momento presente que o toca. Quer dizer, a noção de repertório de ações, neste caso, pode ser compreendida como uma dança dos elementos fundados na experiência de musicar (SMALL, 1998) dos músicos e nas representações que os permitem dizer algo singular na música e entrar em sintonia com os outros (influenciando diretamente as formas pelas quais os músicos revisitam o corpo como arquivo, comunicam algo na música e constroem significados). E essa parece ser a chave principal para que o corpo seja revisitado e reinventado no momento da performance.

Oconstructo do modelo conceptual de análise (quarta aproximação)

O modelo conceptual de análise que este estudo seguirá parte de dois estímulos específicos: um deles corresponde às narrativas dos músicos colaboradores e o outro surge a propósito da leitura de uma literatura sensível a essas narrativas ${ }^{11}$.

Este estudo contou com a participação de oito músicos/performers colaboradores, que responderam a um conjunto de questionamentos de forma dissertativa. Apesar de partirmos de um repto inicial, que aponta para um conjunto de questionamentos fundamentais, a intenção primeira foi deixar os colaboradores livres para se moverem na construção de uma narrativa. Optamos por trabalhar com músicos que possuíssem experiência musical no âmbito das práticas associadas à música popular, por acreditar na liberdade comumente creditada a esse tipo de prática, reconhecida pelos próprios músicos. Nesse domínio performativo particular, espera-se que os performers imprimam e/ou ponham cá para fora algo de novo para acrescentar à música, sobretudo quando tocam em conjunto, o que complexifica os modos através dos quais estes operam os processos de arquivamento e revisitação de um corpo enquanto arquivo.

11 Na verdade, as narrativas e os feedbacks que pouco a pouco fomos tendo dos músicos nos encaminharam rumo ao contato com essa literatura. 
Sob esta ótica, pode-se estruturar o seguinte modelo ilustrativo:

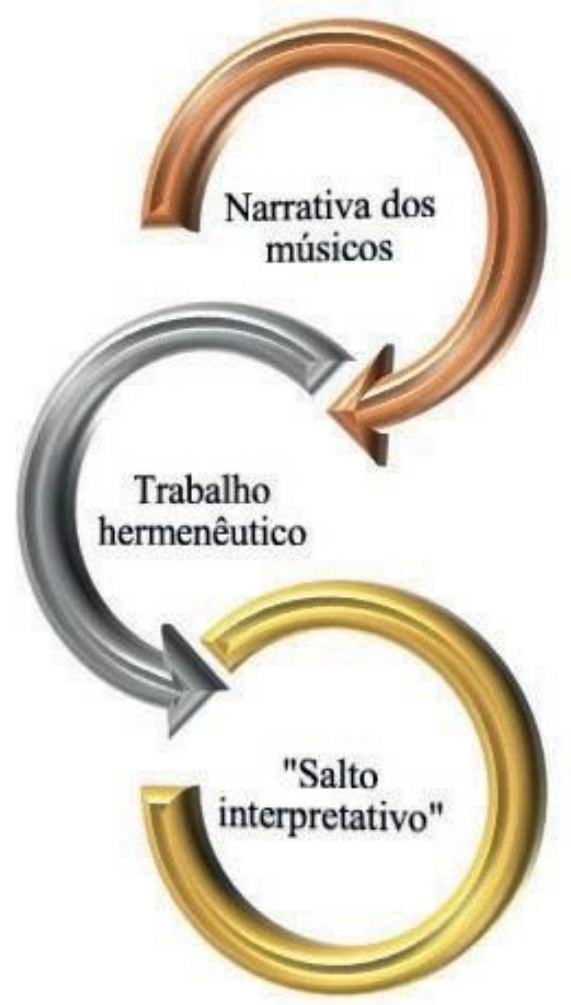

Figura 1 - Núcleo ilustrativo do modelo conceptual de análise. Fonte: Elaborada pelos autores

Da forma como enxergamos, cada uma dessas narrativas está atravessada por experiências e saberes sensíveis, o que resultou num complexo trabalho de interpretação e análise. Isto significa que das narrativas pessoais emergem vários significados, e estes, por sua vez, revelam elementos importantes para a explicação das ações e/ou criações dos performers no que se refere à percepção que eles têm do corpo como arquivo. Contudo, inspirados em parte nos trabalhos do sociólogo peruano Danilo Martuccelli (2007, 2012), quando nos pusemos reflexivos com relação ao trabalho hermenêutico das narrativas, chegamos à conclusão de que nesse trabalho de interpretação existe sempre um "salto interpretativo" 12 necessário. Como diria Clifford Geertz (2008), "interpretar o que acontece" é o cerne do que nos propomos fazer na pesquisa acadêmica.

Parece consensual a ideia de que o corpus teórico é produzido desde conteúdos empíricos. Todavia, por vezes, podemos encontrar correntes de pensamentos que se movimentam num sentido de eliminar o salto interpretativo através do qual cada um de nós conceptualiza, a partir do material produzido, o sumo principal para o trabalho de análise (por exemplo: se uns saltam muito pouco, outros saltam demasiado, e assim por diante). Então tudo está na natureza deste salto. No nosso caso, a intuição primeira foi valorizar o caráter do que chamamos aqui de "salto interpretativo". Ou seja, a extração dos significados a partir da análise das narrativas. Aos nossos olhos, não é na neutralidade que se constrói o saber. É preciso interpretar o mundo.

12 A convergência de pensamento entre Martuccelli $(2007,2012)$ e Clifford Geertz (2008) exprime que o "salto interpretativo" pode ser compreendido, nas linhas da presente abordagem, como um olhar intuitivo sobre a análise das narrativas exprimidas pelos colaboradores de uma pesquisa. 


\section{Quando a banda toca: a narrativa dos músicos}

Da forma como decidimos trabalhar empiricamente com a problemática do "arquivar performances", buscamos extrair das narrativas dos músicos as percepções de como é que as acumulações que vão sucedendo numa lógica de arquivo se rebatem sobre um corpo presente, tendo em conta as suas experiências no domínio das práticas performativas em música popular. As narrativas seguem linhas polifônicas de pensamento, com zonas de contato onde os significados ora se encontram, oradivergem.

Retomamos as inquietações de partida, diluindo-as em três questionamentosque nos guiam no inquieto tentame analítico sobre suas respostas, expondo-as em três partes:

- Primeira inquietação: quando pensamos em guardar essas práticas, onde é que as guardamos? E, se guardamos, o que efetivamente guardamos?

- Segunda inquietação: considerando o efêmero da performance musical, de que forma a experiência vivenciada neste ato pode se converter em um conjunto de significados arquivados em um corpo?

- Terceira inquietação: de que modo estes saberes sensíveis podem ser revisitados? $\mathrm{E}$, ao serem revisitados, como podem ser selecionados frente à situação de performance musical?

\subsection{Primeira inquietação}

Face às teias de significados que atravessam as narrativas, uma percepção inicial nos salta aos olhos: a heterogeneidade do pensar e agir em contexto de performance. Noutros termos de sentido, visualizamos uma via de mão dupla ou até contraditória. Uma delas aponta para um corpo-memória dinâmico que é ativado pelos afetos no momento presente em que o performer se encontra lançado. De outra forma, a segunda faz emergir uma concepção de corpo-mecânico racional e biológico.

Os actantes se movimentam em várias direções, como forma de penetrar o corpo como arquivo. Em primeiro lugar, do ponto de vista dos músicos, o que está em jogo nesse processo de arquivar performances parece estar dividido por uma linha imaginária que corta as dimensões do consciente e do inconsciente. Para Antônio Oliveira (2020), "Pensamos em guardar essas práticas ou seriam incorporadas como memória-hábito? Se há uma questão na memória crucial é a questão do afeto [...]. O afeto é o motor das lembranças" (OLIVEIRA, 2020). Essa visão sensível do corpo é corroborada por outros colaboradores. Sintetizando as perspectivas, a chave principal para o arquivamento de performances se traduz "naquilo que [...] nos tocou. Guardamos aquilo que nos inquietou, nos surpreendeu, nos impressionou, [ou até] aquilo que nos emocionou" (SOUSA, 2020).

Ao ir juntando os retalhos dispersos nessa teia de relações, apreendemos uma coisa: numa situação de performance musical, tudo depende do momento em que o performer se encontra lançado. E, nesse momento, como dizem os músicos, estamos 
acumulando aprendizados. Mas não acumulamos e/ou guardamos de qualquer forma. Guardamos aquilo que realmente importa para nós. Isto é, aquilo que nos toca, que nos comove e que nos move rumo a novas criações. Algo decisivo não só para a revisitação do que guardamos, mas também para a apreciação do que efetivamente guardamos, está na noção do que Fausto Pizzol (2020) chamou de "mapas mentais", uma espécie de cartografia imaginária que ele associa "[...] a imagens e textos [metafóricos]" (PIZZOL, 2020).

Largadas nesse emaranhado de campos de automodelagem e representações de si, aparecem, por sua vez, outras experiências, mais especificamente uma concepção de corpo-mecânico e/ou racional, num sentido biológico. Isso porque são múltiplas as dimensões do trabalho musical. Na sua própria voz: "Eu só guardo aquilo que procuro pôr em prática na minha performance" (GOMES, 2020). Ou, de modo semelhante: "Guardamos os movimentos físicos de uma determinada passagem e o conhecimento das notas e dificuldades de passagens mais difíceis" (PINHO, 2020).

De uma forma ou de outra, as diferentes possibilidades de resposta para essa primeira inquietação parecem estar sujeitas ao status que, enquanto performers, estamos dispostos a conceder à música como cultura. Esta é a expressão da ideia de que esse distanciamento consiste numa ausência de afetividade posta em prática numa dada situação de atuação - seja ela numa sala de estudo individual ou numa situação de performance com audiência. Nestas situações, parece incidir uma aflição que negligencia emoções e as aberturas do presente, insistindo, pelo menos no momento em que estão a fazer música, numa imersão nas considerações previamente programadas para acontecer.

Por outro lado, quando pensamos onde guardamos a música e o que efetivamente guardamos, a característica mais marcante expressada nas narrativas aponta para um significado que não permite ruptura significativa entre aquilo que "tencionamos mecanicamente fazer" e a dimensão "humana do fazer". Estas não se sobrepõem umas às outras. Elas dialogam entre si e são profundamente agregadoras de outras vozes possíveis - ou seja, permitem sempre pôr outras vozes na conversa -, podendo ser ativadas ou não numa situação de performance.

A complexidade dos discursos atinge o limite quando o processo impõe, dia após dia, o esforço da autopromoção - tão comum nos dias atuais -, desafiando, por consequência, combinar unicamente duas atitudes fundamentais em relação à realidade: o engajamento e a autoanálise. Na prática, "todo o processo de aprendizagem na preparação de uma performance é uma tentativa desenfreada de perfeição, [quer dizer, de] 'arquivar'/estabilizar a melhor versão já estudada de determinada obra" (SILVA, 2020). O performer, por vezes, armazena "[...] padrões de execução musical em decorrência do estímulo à repetição, o que contribui no desenvolvimento da memória sinestésica" (SILVA, 2020).

\subsection{Segunda inquietação}

Quando tentamos resumir o que de mais importante pode caracterizar a existência da música, chegamos à conclusão de que trabalhamos com algo que efetivamente não 
sabemos muito bem precisar o que é. Temos que assumir isso. Digamos que a música seja "qualquer coisa" que "acontece", e, para "acontecer", é preciso fazer música. O fato é que a música, como fenômeno, não só possui uma existência extremamente sensível no sentido de que nos foge como realidade, como também arrasta um caráter eminentemente temporal. Quer dizer, jamais poderá repetir-se exatamente. Entretanto, pode proveitosamente gerar novos acontecimentos, promover interlocuções e diferentes jogos de identificação (SARDO, 2010; 2018). Dito isso, a grande questão é saber como tal experiência pode ser comunicada em uma performance que, por consequência, gera significados a serem ou não arquivados em um corpo.

$\mathrm{Na}$ contribuição franca e direta que deram os nossos colaboradores a este repto, tão diversa entre elas no tom e na aspiração, as narrativas transitam em jogos que envolvem estímulos, acasos e afetos, emoções, padrões de coativação ${ }^{13}$ e mecanicidade. Essa trama de relações, bifurca-se entre um passado incorporado e um presente completamente aberto e incerto, no qual os significados podem ser ressignificados.

Quando falamos das nossas experiências passadas somos guiados pelo filtro das emoções, "o que faz com que transformemos [...] a nossa experiência" (OLIVEIRA, 2020). Então, o estímulo fundamental está justamente nas emoções. Para Oliveira (2020), os saberes ficam retidos na nossa memória a partir desses estímulos. Quanto a sua seleção, frente a situação de performance, adviria do que ele chamou de "processo criativo de reutilização mnemônica" (OLIVEIRA, 2020). A elaboração desses suportes de memória tende a ser diversa, ainda mais no que toca a prática da música, onde qualquer reflexão sobre a prática está assente num complexo jogo de imaginação, de (des)classificação e de paradoxos.

Para Elielsom Gomes, "se a performance pode se converter em um conjunto de significados, se trouxer aquilo que eu tenho como propósito na performance a reflexão" (GOMES, 2020). Na concepção de outros, o que fica arquivado em um corpo é, no fundo, fruto de algo muito mais amplo. Ou seja, o que fica retido é "o processo no qual passamos quando nos dedicamos a aprender uma música para peformá-la" (BARROS, 2020 - Sublinhado nosso).

Para encurtar o caminho e ser bem claro, "o indivíduo acessa em si mesmo, todos os processos de aprendizagem no qual viveu ao longo da carreira, para aplicar [...] em uma performance" (BARROS, 2020). Do ponto de vista da tradição eurocêntrica, cada performance é objetificada para se tornar concreta, e torna-se concreta a partir do momento em que se consegue executá-la. Ou, pelo menos, aquilo que o performer acredita ter conseguido executar.

Em síntese, de acordo com os marcos simbólicos extraídos das narrativas, o conjunto de significados arquivados em um corpo vai sempre depender da vivência musical do indivíduo. Se, para uns, isso "vai refletir desde o processo da aprendizagem da performance [considerando os padrões de repetição (SILVA, 2020, PINHO 2020) até o seu momento real de [concretização] [...]" (BARROS, 2020), para outros, "vai depender da conexão entre a performance e o corpo, onde as memórias do corpo e os impactos sensitivos causados pela performance serão os conectores desta ação" (SOUSA, 2020).

13 No tocante à Coactivação, esta diz respeito ao estudo intenso de uma obra, no qual os performers desenvolvem um 'piloto automático' de estudo. ver Jorge Correia (2002). 


\subsection{Terceira inquietação}

Face as inquietações anteriormente expostas, e sendo a classificação vista como feedbacks genéricos à maneira como nossa percepção das coisas é afetada pelo momento presente em que nos encontramos lançados, toda a discussão entra mais em foco.

De acordo com as narrativas em análise, entender como saberes sensíveis podem ser revisitados, e como podem ser selecionados frente a uma dada situação de performance musical, vai depender, num primeiro momento, do modo como cada um conceptualiza/significa, no interior das suas próprias vivências individuais, o fenômeno performativo.

Por um lado, assumimos a performance como uma experiência eminentemente temporal. Isto é, devemos sim ter como objetivo o comprometimento de reviver, no momento da execução, a narrativa emocional, como uma habilidade de reagir aos impulsos e estímulos ocasionados no momento em que a performance musical acontece, num processo criativo. Mas, por outro lado, tendemos validar o ato performativo também como uma espécie de reprodução automática do que foi memorizado e estudado individualmente. Para Barros (2020):

Tudo é revisitado conforme [...] as transformações vivenciadas, [estas] sugerem aprendizados singulares e empíricos do fazer musical e são selecionados de acordo com a experiência de performance que cada indivíduo tem. É neste momento que entramos em fluxo: é quando selecionamos naturalmente [...] [ou] de maneira automatizada, os nossos arquivos através da nossa experiência musical. [...] Um ato de pura criação, de pura improvisação, entretanto, tudo de modo consciente (BARROS, 2020).

O paradoxo aqui é flagrante. Digamos que o momento da performance é o "presente" que estamos experimentando. Se "eu sei o que estou experimentando", então "eu não estou experimentando" efetivamente a criação. Vamos reformular a ideia. Partindo do entendimento de que o momento da performance é único, em termos de composição ou invenção musical, se eu souber o que é "aquilo" que estou inventando, já não estou mais inventando este "aquilo". Esta concepção supõe que o indivíduo se encontra atravessado por diferentes mecanismos deaspiração.

Uma outra estratégia possível para revisitar os saberes arquivados pode ser "vivenciando momentos semelhantes aos quais foram desenvolvidos" (MORAIS, 2020; GOMES, 2020). A cor, o sabor, o que soa, como soa "o momento" (passado) dentro do mesmo momento (presente), embora tenha consciência de que não existem momentos iguais. Nalguns casos, sentimos que é preciso olhar para o momento (aquele que está guardado) que está fora do momento (aquele que estamos a viver no presente performativo). É nesse entre dois [passado e presente] que ocorre a reflexividade, onde o per- 
former faz escolhas e atualiza a herança de aprendizados que carrega consigo.

Boa parte das interpretações apontam para o fato de que é através da prática instrumental diária que o indivíduo consolida processos de armazenamento de saberes. Estes são revisitados frente a uma situação real de performance (SILVA, 2020), na medida em que são recriados. No âmbito da música popular, especialmente "em contextos de improvisação, [...] uma parte dos saberes [também] advém de uma certa automação combinada ao aspeto criativo da memória" (OLIVEIRA, 2020).

Não obstante, muitos dos colaboradores admitem "nunca ter refletido sobre como [...] [podem] revisitar este tipo de saber" (PIZZOL, 2020), embora reconheçam também que arquivam diariamente infindáveis conteúdos, evidenciando que esta pode ser uma operação um tanto inconsciente.

Nada sintetiza tão bem estas narrativas quanto as ideias de Correia (2005), quando afirma que nossas performances não são motivadas apenas pelo conhecimento [ocidental] que se pode ter sobre a música. Para Correia (2005), "[...] é tudo o que possa estimular a nossa reação afetiva com a música” (CORREIA, 2005, p. 04). Quer dizer, reações emocionais/afetivas ao conteúdo das notas de programa, o contexto histórico ou, se quisermos, até o estilo da obra. E não só. "Memórias emocionais de experiências passadas disparadas por associação livre a qualquer momento durante a performance musical; reações miméticas e emocionais aos movimentos e ações dos performers [...]" (Correia, 2005: 04). Tudo isso está, de alguma forma, embutido no que chamamos aqui de corpo-arquivo, num sofisticado jogo entre classificação, desclassificação, reclassificação.

Em suma, aparece latente nas narrativas dos músicos a concepção de que a repetição das ações mecânicas e desenvolvimento de automatismos são importantes, mas não podem ofuscar a produção de reações e estímulos, que podem ocorrer através da relação que o performer exerce em tempo real tanto com o "terreno-corpo-arquivo" quanto com o "terreno" enquanto cenário presente da performance (as relações com o público e com os acontecimentos à sua volta), permitindo que algo de novo brote na atuação.

\section{Será o pensamento final?}

Não há coisa em si — previamente dada — que pensamos meramente existir, como a música, mas o pavor simbólico dela enquanto um saber estático (inquebrável), que julgamos infundado. Infundado porque as consequências simbólicas e intelectuais que comumente se supõe a partir de uma lógica dominante decorrem de uma operação classificatória. Na verdade, não decorrem dela, mas sim das "recompensas" prometidas àqueles que se mantêm em lugar seguro. Acreditamos que esse discurso é ilusório.

Para encurtar o caminho e ser mais claro, não defendemos a classificação. Entendemo-la como uma violência epistemológica. A nossa proposta é justamente na desclassificação, uma operação capaz de fazer emergir aquilo que se encontra oculto (um conhecimento-outro). Foi nesse sentido que tentamos refletir aqui sobre as práticas musicais e as formas através das quais nos relacionamos com elas como performers. Para isso, utilizamos a noção de corpo-arquivo não só como forma de pensar a aplicação do 
conceito no domínio da Música, mas sobretudo de perspetivar a prática da música em si como a construção de um saber inacabado.

A areia movediça conceptual para a qual pode conduzir uma espécie de teorização enraizada sobre corpo-arquivo é evidente naquela que, aos nossos olhos, ainda é uma das melhores aproximações gerais ao que a música pode expressar e/ou comunicar: a narrativa individual dos próprios músicos.

As narrativas analisadas neste artigo definem o corpo-arquivo como: o legado social que o músico adquire das suas experiências ou dos grupos dos quais faz parte; uma forma de guardar vivências; uma espécie de comportamento apreendido e armazenado; um conjunto de saberes para, de forma consciente ou inconsciente, serem ajustados conforme o momento da atuação; e etc. Diante dessa difusão de impressões, mesmo a noção de corpo-arquivo um tanto comprimido e não totalmente padronizado, que seja ao menos coerente e que tenha um argumento mais ou menos definido a propor, representa uma evolução.

O conceito de corpo-arquivo que nós defendemos é essencialmente hermenêutico. Acreditamos que os músicos são atores sociais atrelados a redes de significados que eles foram tecendo ao longo das suas trajetórias individuais. O corpo-arquivo são essas redes e a sua análise. Não num sentido classificatório, com leis rígidas e significados previamente estipulados, mas como algo impreterivelmente desclassificado, a procura de sentido.

A classificação é profundamente sedutora - talvez, um mal irremediável. Aquilo que ela quer que nos preocupemos nos torna cegos de outras realidades possíveis. Corremos perigo. O perigo de que nossa percepção crítica se conforme diante das realidades. O perigo de que nosso intelecto seja encolhido ou reduzido a uma lógica dominante, aquela mais conveniente "para mim" ou "para você" num dado momento. O perigo de que nossas simpatias sejam restringidas pelas escolhas internalizadas e valorizadas pela nossa sociedade, e assim por diante.

Não, esse não será um pensamento final. A análise do corpo-arquivo é (ou, pelo menos deveria ser) um desvendar dos significados, um exame dos rastros deixados pelas ações, um rascunho de conclusões explanatórias baseado nas mais plausíveis suposições e não a descoberta do "todo significado". É uma cartografia da sua paisagem transitória e que não cabe no corpo - embora encontre lá abrigo seguro para morare se reinventar - porque é fruto de um saber inacabado.

\section{Referências}

BARROS, Klênio. A viagem da língua e tudo o que vai com a língua: música popular brasileira e interlocução de culturas nos espaços noturnos da cidade do Porto. In: CONGRESSO INTERNACIONAL "PELOS MARES DA LÍNGUA PORTUGUESA", 3., 2016, Aveiro. Livro de Resumos [...]. Aveiro: UA Editora - Universidade de Aveiro, 2016.

BERGER, Peter L.; LUCKMANN, Thomas. A construção social da realidade. Lisboa: Dinalivro, 2010. 
CORREIA, Jorge Salgado. Investigating Musical Performances as Embodied Socio EmotionalMeaning Construction: Finding na Effective Methodology for Interpretation. 2002. Xxf. Tese (Doutoramento em Música) - Universidade de Sheffield, Inglaterra, 2002.

CORREIA, Jorge Salgado. Utopia E Música. E-topia: Revista Electrónica de Estudos sobre a Utopia, n. 04, 2005. ISSN 1645-958X. Disponível em: http://www.letras.up.pt/ upi/utopiasportuguesas/revista/index.htm. Acesso em: 29 maio 2015.

CÔRTE-REAL, Maria de São José. Música e Migração. Migrações, Lisboa, n. 7, out. 2010.

CÔRTE-REAL, Maria de São Jose. Revendo cidadania: migração e fado no jogo de identidades nos Estados Unidos. Migrações, Lisboa, n. 7, out. 2010.

DERRIDA, Jacques. Mal de arquivo: Uma impressão freudiana. Rio de Janeiro: Relume Dumará, 2001.

GARCÍA GUTIÉRREZ, Antonio L. Cientificamente favelados: uma visão crítica do conhecimento a partir da epistemografia. Transinformação, Campinas, v. 18, n. 2, may/ aug. 2006. Disponível em: http://dx.doi.org/10.1590/S0103-37862006000200002 Acesso em: 20/12/2019.

GARCÍA GUTIÉRREZ, Antonio L. Desclasificados: pluralismo lógico y violencia de la clasificación. Barcelona: An-thropos, 2007.

GARCÍA GUTIÉRREZ, Antonio L. La organización del conocimiento en el nuevo orden transcultural: del totalitarismo a la desclasificación. Brazilian Journal of Information Science, v. 8, n. 1-2, parte I: 19, parte II: 34, 2014. Disponível em: http://revistas.marilia. unesp.br/revistas/in- dex.php/bjis/issue/view/289. Acesso em: 1 jan.2020.

GARCÍA GUTIÉRREZ, Antonio L. En pedazos: el sentido de la desclasificación. Madrid: ACCI, 2018.

GARCÍA, Miguel A. Archivos sonoros o la poética de un saber inacabado. ArteFilosofía, 11, 36-50. 2011.

GEERTZ, Clifford. A interpretação das culturas. I. ed., IS. reimpr. Rio de Janeiro: LTC, 2008. 323p.

HISTORIAS debidas VIII: Silvia Rivera Cusicanqui. [S. I.: s. n.], 2018. 1 vídeo (56 min). Publicado pelo Canal Encuentro. Diponível em: https://www.youtube.com/ watch?v=1q6HfhZUGhc. Acesso em: 8 out. 2019.

LANGER, Suzanne. Philosophy in a newkey. 3. ed. Cambridge, MA: Harvard University Press, 1996. 
LATOUR, Bruno. On recalling ANT. In: LAW, J.;HASSARD, J. (Orgs.). Actor-network theory and after. Oxford: Blackwell Publishers, 1999. p.15-25.

LATOUR, Bruno. Reagregando o social: uma introdução à Teoria do Ator-Rede. Salvador: Ed. UFBA; Bauru: Ed. USC, 2012.

MARTÍNEZ, Sílvia. De Sul para Sul: diáspora indo-paquistanesa e práticas culturais recentes em Espanha. Migrações, Lisboa, n. 7, out. 2010.

MARTUCCELLI, Danilo. Gramáticas del individuo. Madrid: Losada, 2007.

MARTUCCELLI, Danilo.; SINGLY, François de. Las sociologías del individuo. Santiago: LOM Ediciones, 2012.

RIBEIRO, Jorge Castro. Migração, sodade e conciliação: a prática do batuque caboverdiano em Portugal. Migrações, Lisboa, n. 7, out. 2010.

SANTOS, Boaventura de Sousa; MENDES, José Manuel. Para uma sociologia das ausências e uma sociologia das emergências. Revista Crítica de Ciências Sociais, n. 63, p. 237-280, out. 2002.

SANTOS, Boaventura de Sousa; MENDES, José Manuel. Para além do pensamento abissal: das linhas globais a uma ecologia dos saberes. Revista Crítica de Ciências Sociais, n. 78, p. 3-46, 2007.

SANTOS, Boaventura de Sousa; MENDES, José Manuel (org.). Demodiversidade: imaginar novas possibilidades democráticas. Lisboa: Edições 70, 2017.

SARDO, Susana. Proud to be a Goan: memórias coloniais, identidades poscoloniais e música. Migrações, Lisboa, n. 7, out. 2010.

SARDO, Susana. O desconforto de escrever sobre música. In: GARCÍA GUTIÉRREZ, Antonio L. En Pedazos: el sentido de la desclasificación. Madrid: ACCI, 2018.

SARTRE, Jean Paul. O ser e o nada: ensaio de ontologia fenomenológica. Trad. P. Perdigão. Petrópolis: Vozes, 2005.

SMALL, Christopher. El musicar: um ritual em el espacio social. Revista Transcultural de Música Transcultural Music Review, n. 4, 1999.

TÉRCIO, Daniel. Arquivar performances ou os paradoxos do corpo-arquivo. Repertório, Salvador, ano 20, n. 28, p. 93-107, 2017.

Entrevistas $^{14}$ : 
OLIVEIRA, Antonio Henrique de. [Entrevista cedida a Erickinson Bezerra e Klênio Barros] 2020. Rio de Janeiro(RJ).

MORAIS, Ricardo Félix de. [Entrevista cedida a Erickinson Bezerra e Klênio Barros] 2020. Natal (RN).

PIZZOL, Fausto Lessa Fernandes. [Entrevista cedida a Erickinson Bezerra e Klênio Barros] 2020. Aveiro (PT).

GOMES, Elielson da Silva. [Entrevista cedida a Erickinson Bezerra e Klênio Barros] 2020. Aveiro (PT).

PINHO, Ivo Amorim. [Entrevista cedida a Erickinson Bezerra e Klênio Barros] 2020. Ovar (PT).

SOUSA, lury Matias de. [Entrevista cedida a Erickinson Bezerra e Klênio Barros] 2020. Aveiro (PT).

SILVA, Pedro Augusto da. [Entrevista cedida a Erickinson Bezerra e Klênio Barros] 2020. Natal $(R N)$.

BARROS, Samuel. [Entrevista cedida a Erickinson Bezerra e Klênio Barros] 2020. Aveiro (PT).

Link para acesso às respostas:

https://drive.google.com/open?id=1N2D-YY5EPMI5ZsF5smilXQOXnc7uV_kn

6 Todos os respondentes do questionamento virtual permitiram a publicação e a menção de seus nomes reais no corpus desta abordagem. 
'Notas de fim'

i Eblima dedica este artigo à S. G. M. R., como forma de expressar eterna gratidão. 